\title{
A Case Study Using ProQuest RefWorks: An Entry Point for Addressing Information Literacy
}

\author{
Katrina Roseler \\ Chaminade University of Honolulu \\ katrina.roseler@,chaminade.edu \\ Elizabeth Park \\ Chaminade University of Honolulu \\ epark@,chaminade.edu \\ Valerie Coleman \\ Chaminade University of Honolulu \\ vcoleman@,chaminade.edu \\ Brooke Carlson \\ Chaminade University of Honolulu \\ brooke.carlson@,chaminade.edu \\ Claire Kendal-Wright \\ Chaminade University of Honolulu \\ claire.wright@,chaminade.edu
}

\begin{abstract}
An interdisciplinary team of university faculty members collaborated to develop an intervention to address a deficiency in student information literacy skills. The team developed video modules that instruct users how to create, use and maintain a ProQuest RefW orks account; a citation management software (CMS) tool that is compatible with Google Docs word processing. The research team collected YouTube and ProQuest RefWorks analytics as well as pre/post survey data from university students who participated in a pilot using the video modules. Results indicate that the modules impacted student information literacy skills; specifically, in-text citation and referencing. Based on the results, we also describe next steps for this research.
\end{abstract}

Keywords: Information Literacy (IL), Citation Management Software (CMS), ProQuest RefW orks, Institutes of Higher Education (IHE)

University faculty members are often called upon to support students learning in interdisciplinary ways. If a student is deficient in prerequisite skills in writing or mathematics, instructors need to be able to provide resources to support the development of these skills in addition to regular course learning activities. The skill set at the center of this research is information literacy; specifically, citation in writing and referencing. An interdisciplinary team of university faculty members worked collaboratively to (1) identify/create resources to support the development of information literacy skills, and (2) pilot the use of those learning resources and tools with students.

\section{Background}

The university where this research took place is a member of the WASC Senior College and University Commission (WSCUC). During the academic year 2014-15, a team of faculty members at the 
university was tasked with evaluating the information literacy of students, a core competency at the university. This core competency team adopted an adapted version of the Association of American Colleges and Universities (AACU) Information Literacy Value Rubric as the tool they would use to evaluate student information literacy. Using this adapted AACU Information Literacy rubric, the team reviewed student artifacts from a cross-section (i.e., various disciplines) of students; typically, at the senior most level of undergraduate education. The team focused on two criteria from the adapted rubric that would comprise the focus of their analysis of student information literacy: (1) extent of information needed and (2) access and relevance. The extent of information literacy addresses research scope as it relates to a research question or thesis; the identification of key concepts and identification of resources related to concepts or research question (Jamieson, 2017; Johnston \& Webber, 2003). Access and relevance address the identification of sources through the use of a search strategy, resulting in the selection of relevant information (Katz \& Elliot, 2017). As a result of the analysis of student artifacts, the core competency team reported that student information literacy was below proficiency in the areas of (1) extent of information needed and (2) access and relevance. Recommendations from the team described the need to engage university faculty to generate ideas to improve students' information literacy. Further, the team expressed the need for greater emphasis on writing and bibliography as a demonstration of knowledge and shared discussion, no matter the discipline.

The report authored by the core competency team that describes the status of students' information literacy prompted the formation of an additional research team. This research team dedicated itself to the identification of skills and knowledge that would support student information literacy. The formation of this research team was the result of a series of events.

The university where the research was conducted received Title III funding (grant \#P031W150002) which allowed for the development of a faculty Center for Teaching and Learning (CTL). One of the primary goals of the CTL is to support faculty in the area of the Scholarship of Teaching and Learning (SoTL). Faculty members often met informally at the CTL and discussed relevant issues related to their teaching. It was during one of these informal discussions that two faculty members began to discuss pathways for supporting student academic writing. These discussions focused on developing students' information literacy skills; a way to support academic writing.

At around the same time that the ideas for addressing student information literacy skills were being discussed, funding for interdisciplinary research was announced as part of the Title III grant. Given the interdisciplinary need for student information literacy skills, these two faculty members reached out to other faculty members from different disciplines to gauge their interest in participating in interdisciplinary research related to this topic. The members that agreed to participate, applied for Title III funding in order to develop, implement and investigate the impact of an intervention on student information literacy. With the approval of their application, the interdisciplinary team began their work and, as a result, each member received a small stipend and completed the SoTL research presented here.

\section{Literature Review}

This literature review provides context for our research within the fields of information literacy (IL) and citation management software (CMS). Also included are a review of research on best practices for CMS as well as an in-depth review of research on ProQuest RefWorks; the specific CMS tool used in this study.

Journal of the Scholarship of Teaching and Learning, Vol. 19, No. 4, October 2019. josotl.indiana.edu 


\section{Information Literacy}

Information literacy encompasses important skills across all areas of life but especially in the educational setting. As a matter of fact, IL is considered an essential competency in the institute of higher education (IHE) across all disciplines (Weiner, 2012). There are numerous definitions for IL but according to The Association of College and Research Libraries (ACRL), the commonly used definition is the ability to:

1. Determine the nature and extent of information needed

2. Access the needed information effectively and efficiently

3. Evaluate information and its sources critically

4. Use information effectively to accomplish a specific purpose

5. Understand the economic, legal, and social issues surrounding the use of information

6. Access and use information ethically and legally (ACRL, 2000)

Since this initial definition established by ACRL, an update has been given to the Framework for Information Literacy for Higher Education (Framework) to address the ever-changing landscape of higher education and information ecosystem (ACRL, 2015). This new Framework focuses on interconnected core concepts, providing broader options for implementation instead of focusing on standards. The updated Framework is organized around following six constructs:

- Authority Is Constructed and Contextual

- Information Creation as a Process

- Information Has Value

- Research as Inquiry

- Scholarship as Conversation

- Searching as Strategic Exploration

Because the new Framework extends to broader concepts and implementation, a new definition is being used:

Information literacy is the set of integrated abilities encompassing the reflective discovery of information, the understanding of how information is produced and valued, and the use of information is creating new knowledge and participating ethically in communities of learning (ACRL, 2015, p. 3)

According to Head, Van Hoeck, and Garson (2015), there are numerous studies addressing IL instruction and assessment including qualitative and quantitative methods for assessing IL. One of the findings by Head et al. (2015) indicates that only 13 percent of high school seniors and college students are information literate. In addition, research by Fitzgerald (2004) describes that the digital native nature of many young people today does not automatically translate to knowing how to conduct research with technology. Research skills are acquired through iterative practice and coaching but often overlooked in IHE (Head, 2007).

IL is considered essential competency associated with educational success, lifelong learning, and workforce readiness. The planning agenda of many IHE often include IL as an expected learning outcome for students (Saunders, 2007; Weiner, 2012). Thus, faculty at IHE are beginning to prioritize students developing skills towards IL competence (Weiner, 2011; Willison, 2012).

A student's ability to discover information and use the information to create new knowledge

Journal of the Scholarship of Teaching and Learning, Vol. 19, No. 4, October 2019.

josotl.indiana.edu 
is one area of IL that is measured in IHE. Multiple studies have been conducted to determine whether students can use research tools to achieve IL. One such research tool is citation management software (CMS), which is used to store and organize literature associated with research. Effective use, storage, and organization of literature can support student academic writing and citation.

\section{Review of Research Citation Management Software (CMS)}

"Citation management software collects citations from various sources, organizes them, and compiles them into a bibliography or list of works cited. The software helps the user create citations in numerous different styles such as APA, MLA, Turabian, and Chicago" (LSU Libraries, 2018, n.p.). If used purposefully, CMS supports IL by keeping organized records of relevant literature associated with academic writing.

There was a time when the only option for organizing bibliographic information was manually completed. However, with advances in technology, ways of organizing and processing information have also advanced. Today, there are many CMS tools that can assist with this process. Research on CMS falls into two generalized categories; implementation and impact. Research on the implementation of CMS describes how university faculty/staff, typically a librarian, develops resources to effectively deploy citation management software tools at a particular school site. Impact studies describe outcomes that result from the implementation of CMS at IHE; particularly best practices. This section of the literature review addresses both.

Towards the end of the 1990s, the notion of integrating bibliography and word processing became possible through different softwares (Tramullas, Sánchez-Casabón, \& Garrido-Picazo, 2015). Proper citation is integral to demonstrating proficiency in IL (ARCL Framework, 2015). Software such as Procite and EndNote/Endlink paved the way for the multitude of CMS programs that exist today. In the early 2000s, RefWorks added a new format to CMS which was web-based instead of a standalone program (Simboli \& Zhang, 2002). This web-based function gave RefWorks an advantage over the previous software because it increased accessibility; now a researcher could access their personal library from any location as long as there was an internet connection. An additional advantage of being web-based was that RefWorks was not dependent on a specific computer platform (Emanuel, 2013). Today, many of the CMS programs include web-based features, even extending those features to be used in collaboration with other researchers.

Another big jump to the development of CMS came with Zotero in 2006; the first open source CMS (Emanuel, 2013). Zotero, which was also web-based, was and is still a free resource that is open to the public. In 2008, Mendeley, another open-source CMS, was released but was not web-based. Many citation management tools exist today, however, RefWorks, Zotero, Mendeley, and EndNote are the four most used by IHE (McMinn, 2011; Benda, Limpitlaw, \& Estelle-Holmer, 2010). Research conducted on CMS reviews and compares these platforms, but there is a fundamental lack of research on how CMS relates to advancing IL in IHE.

Best Practices for CMS. Studies that address best practices for supporting and implementing citation management tools describe the importance of providing pathways for developing student competency with citation skills. Best practices research suggests (1) competencies and knowledge levels related to citation skills, as well as (2) focuses on the best practices for supporting, recommending, and teaching tools for the many aspects of citation management (Childress, 2011). There is a growing voice that asserts the need to provide students with instruction on how to use CMS tools (Hull, Pettifer, \& Kell, 2008; Duong, 2010). The management of search processes and results are skills associated with IL (ACRL Framework, 2015).

Understanding the structure and function of citations is also important, because the information conveyed via research has value, and should be treated ethically (ARCL Framework, 
2015). Childress (2011) provides the following competencies and skills related to the citation:

- Recognizing citations and understanding their function in research.

- Knowing what a citation is and understanding the concepts of citation styles

- And familiarity with writing formatting, (i.e., such as in-line citations, footnotes, endnotes, and bibliographies or Works Cited).

- Understanding the difference between citations for common item types and why this matter. For example, are they looking at a citation for a book, book chapter, article, newspaper, or blog post? What does the item type tell them about the cited resource?

- Understanding what constitutes plagiarism, the differences between quoting and paraphrasing, and why it is important to cite your sources.

- Knowing where to find style guides, either quick guides or manuals, to assist them with formatting their own citations and bibliographies.

- Understanding how to use the guides and have an understanding of what information can be found in the suggested resources.

- At more advanced levels, a familiarity with citation generators or managers might be in order. If this is the case, it is helpful for students and researchers to have a basic understanding of the key uses and features of citation management tools, such as collecting, organizing and sharing citations or word processor integration (p. 148).

Childress (2011) strongly recommends that the university library provide a systematic approach for implementing the use of CMS such as, (1) creating a central resource for citation information, and (2) developing training materials and programs for reference staff.

RefWorks. RefWorks introduced ProQuest Flow ${ }^{\mathrm{TM}}$ as a cloud-based, open-source citation management tool in 2013 (ProQuest takes RefWorks to the next level with Flow ${ }^{\text {TM }}$, 2013). The advantage of this tool was that it was free and easily integrated with Google Doc word processing through an add-on. Two years later, RefWorks decided to merge RefWorks and ProQuest Flow ${ }^{\mathrm{TM}}$ to create ProQuest RefWorks (ProQuest reimagines RefWorks platform to streamline the research and collaboration process, 2016). Because ProQuest RefWorks is so new, we were not able to identify any research associated with this specific CMS tool.

\section{Information Literacy and CMS}

There are two central themes that we identified within the research on the intersection of IL and CMS. Theme one: CMS is a tool to support the development of IL. Theme two: The responsibility for developing students' IL should be dispersed equally among all university faculty and not the sole responsibility of the librarian.

Theme one: CMS is part of information literacy. A growing number of studies suggest that there is a need to support IL, including various forms of citation management. One study describes how that support should be laid out in the four-year undergraduate university. The findings identify that the sophomore year is when citation management skills should be introduced as part of the IL plan (Kuglitsch \& Burge, 2016).

There is a dearth of research regarding the role of librarians, faculty, or administrators for providing instruction related to in citation management. Research on citation management is focused on the reviews, comparisons, and evaluations of CMS which quickly becomes outdated due to constant advancements in technology (Butros \& Taylor, 2010; Gilmour \& Cobus-Kuo, 2011).

Theme two: Information literacy is the responsibility of all. In addition to describing when different IL skills should be taught in IHE, there are many studies that indicate that IL is not only the responsibility 
of the librarians, but should be a collaborative effort among librarians, faculty, and administrations (D'Angelo, Jamieson, Maid, \& Walker, 2017).

Many researchers agree that information literacy is central to educational success in IHE. What remains to be addressed is the discrepancy between faculty expectation and the actual level of students' information literacy who are entering universities. Evidence indicates that librarians have tried to address this issue by providing workshops and supports for students (Kuglitsch \& Burge, 2016). Further, some faculty integrate the basics of citation and referencing into course activities (Johnston \& Webber, 2003; Katz \& Elliot, 2017). Despite these efforts, there needs to be a stronger sense of responsibility from faculty to address the need to develop student information literacy. This responsibility needs to be an interdisciplinary effort as information literacy is a university-wide goal for many at IHE (Weiner, 2012; Willison 2012; Wu \& Kendall 2006).

\section{Research question}

Given the cross-disciplinary nature of IL skills, and based on prior research conducted on the implementation of CMS, our team wants to determine the impact of a series of videos developed to support students' use of CMS. Specifically, we are interested in determining whether the use of ProQuest RefWorks has any impact on student's IL.

\section{Methods}

\section{Research context}

The described study was implemented at a private university in the state of Hawaii. The day undergraduate enrollment is nearly 1200 students. These students are $71 \%$ female and $29 \%$ male. The day undergraduate student population is ethnically diverse: 38\% Asian, 21\% Native Hawaiian, 14\% White, 13\% two or more ethnicities, 5\% Hispanic, 3\% African-American, 1.5\% Non-resident Alien, $0.5 \%$ Native American, and 4\% unknown. The university also has online undergraduate and graduate programs. Given the flexible on again, off again nature of online programs, demographic information about online students is more challenging to maintain, and we are not reporting information about these students.

The participants in this research were solicited from 3 of the university's 6 academic divisions, including day undergraduate, online undergraduate and graduate programs. We purposefully targeted participants from different divisions and from a cross-section of day and online programs in order to address the core competency of IL, a central tenet for university accreditation and a goal for many IHE (Weiner, 2012; Willison 2012; Wu \& Kendall 2006).

\section{Information literacy}

The team that formed to address student IL defines it using the definition developed by the ACRL. The ACRL Framework states that "Information literacy is the set of integrated abilities encompassing the reflective discovery of information, the understanding of how information is produced and valued, and the use of information in creating new knowledge and participating ethically in communities of learning" (ACRL, 2015). 


\section{Identifying and creating resources to support information literacy}

In the AY 2015-2016, a team of interdisciplinary faculty developed online resources to support the development of student information literacy. The interdisciplinary team was comprised of faculty members representing 4 of the 7 divisions at the institution: Education, Humanities/Fine Arts, Behavioral Sciences, and the Library. Faculty members from these divisions identified video tutorial resources to support students with the use of Google Doc word processing tools from Lynda.com. Further faculty members created video tutorials for account creation and use of ProQuest RefWorks. The video tutorials for ProQuest RefWorks and Google Docs are available through a LibGuide on the library's website. At the time of video tutorial development, ProQuest RefWorks was a free online citation management tool. While other free citation management tools (i.e., Zotero, Mendeley) were available at the time of tutorial development, ProQuest RefWorks was chosen because had the advantage a Write-n-Cite feature, or "add-on”, which is compatible with Google Docs.

\section{Instruments/Data sources}

Three different data sources were used to evaluate the impacts of the ProQuest RefWorks intervention; YouTube analytics, ProQuest RefWorks Analytics, and Pre/Post survey responses. YouTube analytics were used as a data source for the number of views of each of the videos created by the team about the following IL tools: (1) creation and maintenance of a ProQuest RefWorks account; and (2) write-n-cite and bibliographic features. ProQuest RefWorks analytics were used as a data source about the number of accounts created as well as the number and types of references that were stored in those accounts.

The research team developed pre and post survey instruments to collect information about the impacts relating to the use of Google Doc word processing software and ProQuest RefWorks citation management software. The pre-survey includes questions related to participant demographics and familiarity and/or skill level with (1) Google Docs, (2) citation in writing and (3) ProQuest RefWorks. The post-survey included the pre-survey questions as well as questions about use frequency for both Google Doc and ProQuest RefWorks.

\section{Participants}

A total of 124 students completed both the pre- and post-surveys. While students from 3 divisions (i.e., Education, Humanities/Fine Arts, Natural Sciences) were invited to participate, complete responses were only received from 2 divisions. We attribute the lack of consistent response to the flexible methods used to implement the Google Docs and ProQuest RefWorks modules. In accordance with our IRB, participation in the research (i.e., survey) was voluntary. Some of the faculty provided instructional time for participants to complete the surveys while other faculty did not; leaving the survey as an optional activity to be completed independently of instructional time. Table 1 shows demographic information about the participant sample. The demographics include division, gender, program information, and ethnicity. Table 2 displays information about the age of the participants.

Table 1. Demographic information about the participants, including a number of participants representing each subgroup as well as the percentage of the sample $(\mathrm{N}=124)$.

\begin{tabular}{rccc} 
Group & Subgroup & \# of participants & \% of sample \\
\hline Division & Education & 97 & 78 \\
\hline
\end{tabular}

Journal of the Scholarship of Teaching and Learning, Vol. 19, No. 4, October 2019. josotl.indiana.edu 


\begin{tabular}{|c|c|c|c|}
\hline & Humanities/Fine Arts & 27 & 22 \\
\hline \multirow[t]{2}{*}{ Gender } & Female & 97 & 78 \\
\hline & Male & 27 & 22 \\
\hline \multirow[t]{3}{*}{ Program } & Day Undergraduate & 41 & 33 \\
\hline & Graduate & 63 & 50 \\
\hline & Online undergraduate & 20 & 16 \\
\hline \multirow{2}{*}{$\begin{array}{l}\text { Online/ } \\
\text { Traditional }\end{array}$} & Traditional & 41 & 33 \\
\hline & Online & 83 & 67 \\
\hline \multirow[t]{10}{*}{ Ethnicity } & Asian/Asian American & 42 & 34 \\
\hline & Native Hawaiian/Pacific Islander & 31 & 25 \\
\hline & White & 26 & 21 \\
\hline & Hispanic/Latino & 13 & 10 \\
\hline & African-American & 3 & 2.4 \\
\hline & Filipino & 3 & 2.4 \\
\hline & Two or more ethnicities & 2 & 1.5 \\
\hline & International/Non-Resident & 2 & 1.5 \\
\hline & Native American & 1 & $<1$ \\
\hline & Unknown/Did not report & 1 & $<1$ \\
\hline
\end{tabular}

Table 2. Age range of the participant sample $(\mathrm{N}=124)$.

\begin{tabular}{ccc}
\hline Age range & Participants & \% of sample \\
\hline $18-25$ & 71 & 57 \\
$26-35$ & 30 & 24 \\
$36-60$ & 23 & 19 \\
\hline
\end{tabular}

\section{Intervention}

The intervention for this research included participants viewing the video modules and creating a ProQuest RefWorks account, however, there was no designated protocol for implementing this intervention. The participants in this study were encouraged to create ProQuest RefWorks accounts in various ways. One faculty member designated class time for students to create ProQuest RefWorks accounts, with the support of a librarian, while others were "highly encouraged" to create a ProQuest RefWorks or similar CMS account for use in course assignments. Two additional faculty members incorporated this activity as part of the online coursework. All faculty members provided access to the video modules as resources for participants, however, none of the faculty members required 
students to view them. No doubt, the variable implementation of the intervention had an impact on the results of this study.

\section{Results}

The results sections provide a description of the three different data sources were used to evaluate the impacts of the ProQuest RefWorks intervention; YouTube module analytics, ProQuest RefWorks Analytics, and Pre/Post survey responses.

\section{YouTube Modules}

Table 3 shows a list of the YouTube modules that were developed to support students with creating a ProQuest RefWorks account and the features associated with this citation management tool. Table 3 also provides information on the number of times each of the video modules were viewed during the data collection period. The video modules are open source; therefore, we make no claims about the correlation between our research participants and these data, however, it does provide useful information to the research team about supporting students as they develop skills using ProQuest RefWorks.

The overview, creating an account, and creating a bibliography were the most commonly viewed videos. Adding a reference manually, choosing a citation style, Manage ProQuest RefWorks Login \& set writing style were the three least viewed videos. The videos on the creation and use of a ProQuest RefWorks accounts were more popular than those related to using ProQuest RefWorks Write-n-Cite features.

Table 3. YouTube video module views related to ProQuest RefWorks for AY 2016-17.

\section{YouTube Videos (ProQuest RefWorks)}

Introduction to ProQuest RefWorks

Creating a ProQuest RefWorks Account

Overview of the ProQuest RefWorks Interface

Library Resources (ProQuest RefWorks)

Adding a Reference from a Database (ProQuest RefWorks)

Adding a Reference Manually (ProQuest RefWorks)

Creating a Bibliography with ProQuest RefWorks

Choosing a Citation Style (ProQuest RefWorks)

Install ProQuest RefWorks Add-on in Google Doc

Manage ProQuest RefWorks Add-on: Login \& Set Writing Style

Manage ProQuest RefWorks Add-on: In-Text Citation

Manage ProQuest RefWorks Add-on: Formatting References
Views for AY 2016-17

157

281

430

131

165

190

35

70

61

87

116

Journal of the Scholarship of Teaching and Learning, Vol. 19, No. 4, October 2019.

josotl.indiana.edu 


\section{ProQuest RefWorks Analytics}

Administrative access ${ }^{1}$ provided the research team with analytics on the creation and use of ProQuest RefWorks accounts. During the data collection period, 195 students created ProQuest RefWorks accounts and a total of 582 publications were added into student ProQuest RefWorks accounts: 324 publications for graduate students and 258 for undergraduate students. 206 students actively used their accounts in the 2016-17 AY, which means that 11 students had ProQuest RefWorks accounts prior to data collection period.

Table 4 shows the types of references added to student RefWorks accounts including journals, magazines, books, ebooks, news/newspapers, encyclopedia and Wikipedia, and websites (including retail websites such as apple.com, walmart.com, and amazon.com). Education resources were, abundantly, the most common type of publications added. This result aligns with the demographic information provided by the participants; $78 \%$ of the sample identified themselves as students in education courses.

Table 4. Types of References added to RefWorks Accounts, September 2016-September 2017

Types of publications Graduate Students Undergraduate Students

\begin{tabular}{lcc} 
Business journals & 0 & 4 \\
Criminal Justice / Law journals & 0 & 14 \\
Education journals & 254 & 24 \\
Education websites & 17 & 3 \\
Encyclopedia & 0 & 2 \\
Wikipedia & 0 & 1 \\
Religion journals & 2 & 6 \\
Science journals & 0 & 119 \\
Science websites & 0 & 16 \\
Social Science journals & 4 & 20 \\
Social Science websites & 0 & 6 \\
Magazines & 2 & 8 \\
News / newspapers & 2 & 14 \\
Nursing & 0 & 1 \\
Dissertation / theses & 17 & 0 \\
Books & 0 & 8 \\
E-books & 5 & 2 \\
University websites & 21 & 0 \\
\hline
\end{tabular}

1 The free ProQuest RefWorks Individual (Premium) account does not include Analytics but access was provided by ProQuest for the purposes of this study.

Journal of the Scholarship of Teaching and Learning, Vol. 19, No. 4, October 2019.

josotl.indiana.edu 


\begin{tabular}{lcc}
\hline Retail websites & 11 & 0 \\
Unknown & 7 & 9 \\
TOTAL & $\mathbf{3 4 2}$ & $\mathbf{2 5 8}$ \\
\hline
\end{tabular}

Table 5 indicates that the highest percentage of references added to ProQuest RefWorks accounts were journals, $76 \%$ for graduate students and $72 \%$ for undergraduate students, followed by websites, dissertations/theses and other types of listed references.

Table 5. Types of references added to RefWorks accounts by Number and Percentage

\begin{tabular}{lcc}
\hline \multicolumn{1}{c}{ Types of References } & Graduate students & Undergraduate students \\
\hline Journals & $260(76 \%)$ & $187(72 \%)$ \\
Websites & $49(14 \%)$ & $26(10 \%)$ \\
Dissertations/Theses & $17(5 \%)$ & 0 \\
News/Newspapers & $2(1 \%)$ & $14(5 \%)$ \\
Books & 0 & $8(3 \%)$ \\
Magazines & $2(1 \%)$ & $8(3 \%)$ \\
Ebooks & $5(1 \%)$ & $2(1 \%)$ \\
Encyclopedia & 0 & $2(1 \%)$ \\
Wikipedia & 0 & $1(1 \%)$ \\
Video & 0 & $1(1 \%)$ \\
Unknown & $7(2 \%)$ & $9(3 \%)$ \\
\hline
\end{tabular}

\section{Pre/ Post Survey response}

In addition to the ProQuest RefWorks analytics, 124 students completed pre and post surveys addressing questions on their perceived level of proficiency using Google Doc, In-text citation, and ProQuest RefWorks. Further, the post-survey included questions about frequency of use for Google Doc, In-text citation and ProQuest RefWorks. We report on our analyses of these pre/post data in the following section.

Google Doc. Figure 1 shows that the greatest pre and post responses of self-reported experience with Google Docs is at a proficient or expert level for aggregated student responses. A paired samples $\mathrm{t}$-test was run to compare the mean pre and post responses, and no significant difference was found between the pretest $(M=3.20$, SD 0.963) and posttest $(M=3.19$, SD 1.001); $t(123)=$ value $0.115, p=$ 0.909. Independent t-tests were run to compare the mean shifts between the two groups and no significant difference was found between undergraduate $(\mathrm{M}=0.0448$, SD 0.80590) and graduate student responses $(\mathrm{M}=-0.0702, \mathrm{SD} 0.75261) ; \mathrm{t}(122)=0.816$ value, $\mathrm{p}=0.416$. 


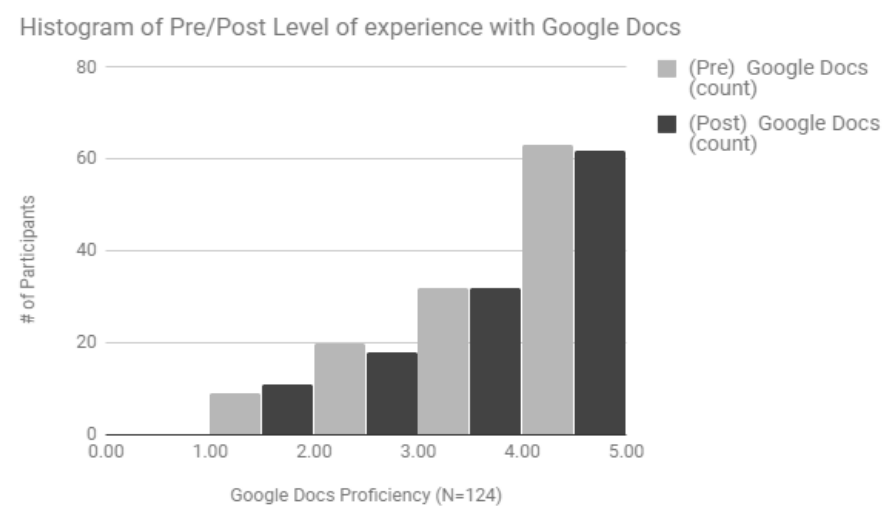

Figure 1. Aggregated (i.e., both DUG and Online programs) survey responses of participant self-reported experience with of Google Docs for the AY 2016-2017 (N=124).

Experience with citation in writing. Figure 2 shows the range of pre and post responses of selfreported experience with a citation in writing. The responses span from novice to expert level and did not appear to change dramatically as a result of the intervention with the Google Doc or ProQuest RefWorks modules. A paired samples t-test was run to compare the mean pre and post responses, and no significant difference was found between the pretest $(M=3.02, S D 0.883)$ and posttest $(M=3.03$, $\mathrm{SD}$ 0.845); $\mathrm{t}(123)=-0.187, \mathrm{p}=0.852$ Independent $\mathrm{t}$-tests were run to compare the mean shifts between the two groups and no significant differences were found between undergraduate $(\mathrm{M}=0.1045$, SD 0.88992) and graduate student responses $(M=-0.0877$, SD 1.03993); $t(122)=1.109$ value, $\mathrm{p}=0.270$.

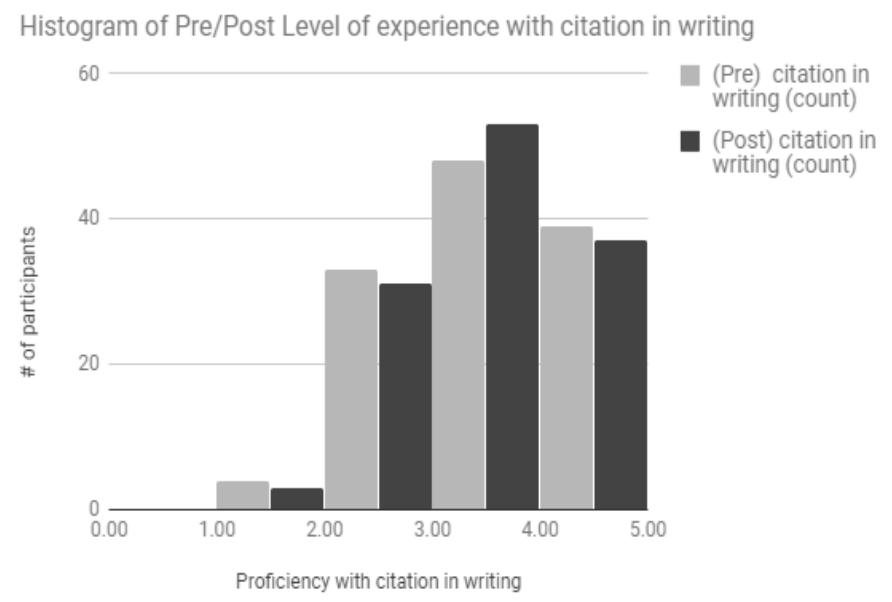

Figure 2. Aggregated (i.e., both DUG and Online programs) survey responses of participant self-reported experience with citation in writing for the AY 2016-2017 ( $N=124)$.

ProQuest RefWorks. Participants in this research, who created ProQuest RefWorks accounts and/or viewed the ProQuest RefWorks modules, self-reported an increase in their proficiency with this citation management tool. Figure 3 indicates a shift from pre, self-reported responses of "no experience with ProQuest RefWorks" to post responses of "intermediate" and/or "proficient" responses. A paired samples t-test was run to compare means, and a significant difference was found between pretest $(M=1.32$, SD 0.669) and posttest $(M=2.40$, SD .0970) aggregate responses; $t(123)=$ $-11.976, \mathrm{p}<0.001$. Independent $\mathrm{t}$-tests were run to compare the mean shifts between the two, groups 
and no significant differences were found between undergraduate $(M=0.9403, S D=1.04273)$ and graduate student responses $(\mathrm{M}=1.2281$, SD .92616); $\mathrm{t}(122)=-1.612, \mathrm{p}=0.110$. Both groups demonstrated an increase in proficiency with ProQuest RefWorks.

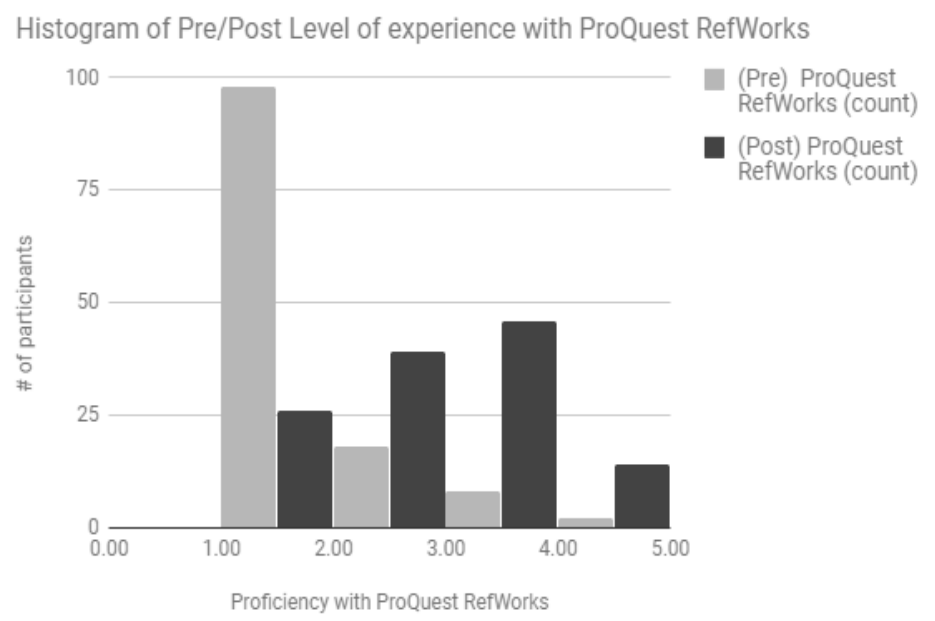

Figure 3. Aggregated (i.e., both DUG and Online programs) survey responses of participant self-reported experience with of ProQuest RefWorks for the AY 2016-2017 (N=125).

Post survey responses for frequency of use

Google Doc. Figure 4 indicates that the majority of the participants in this study use Google Docs every day within the course where the data collection occurred $(M=4.02)$. Independent t-tests were run to compare the means between the two groups and no significant differences were found between undergraduate $(M=3.91, S D 1.138)$ graduate student responses $(M=4.16, S D 0.621)$; $t(122)=$ $-1.532, \mathrm{p}=0.129$.

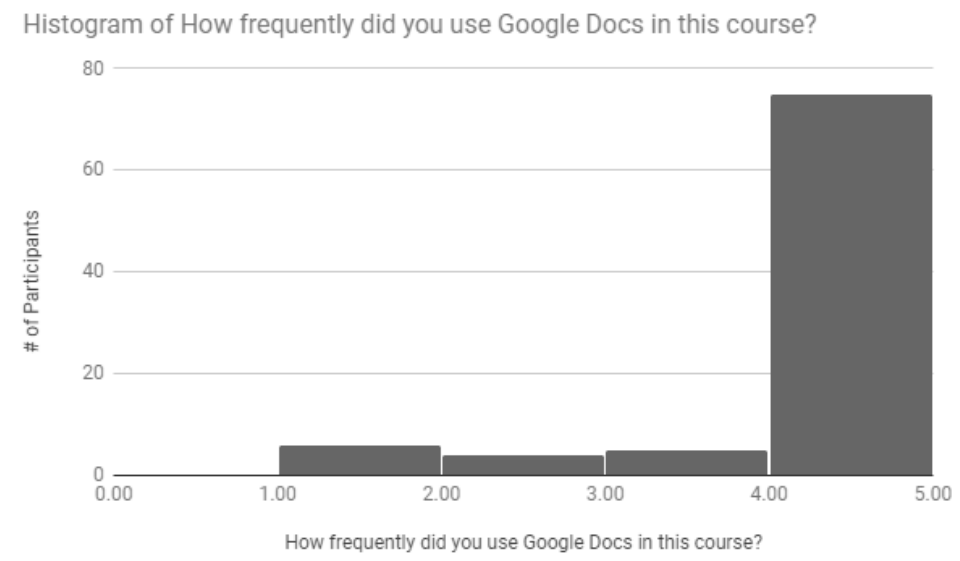

Figure 4. Aggregated (i.e., both DUG and Online programs) survey responses of participant self-reported frequency of Google Doc uses for the AY 2016-2017 (N=124).

Frequency of citation in writing. Figure 5 indicates that the majority of the participants in this study use citation in their writing weekly or every day $(M=3.93)$. Figures 6 and 7 show differences in the frequency of use of citation in writing between undergraduate and graduate samples. Undergraduate 
students' responses were divided between weekly or daily, while most graduate students used the citation in writing on a daily basis. Independent $\mathrm{t}$-tests were run to compare the means between the two groups and there was a significant difference in the scores for undergraduate students $(\mathrm{M}=3.79$, $\mathrm{SD}=0.845)$ graduate student responses $(\mathrm{M}=4.09, \mathrm{SD}=0.544) ; \mathrm{t}(122)=-2.358, \mathrm{p}=0.020$.

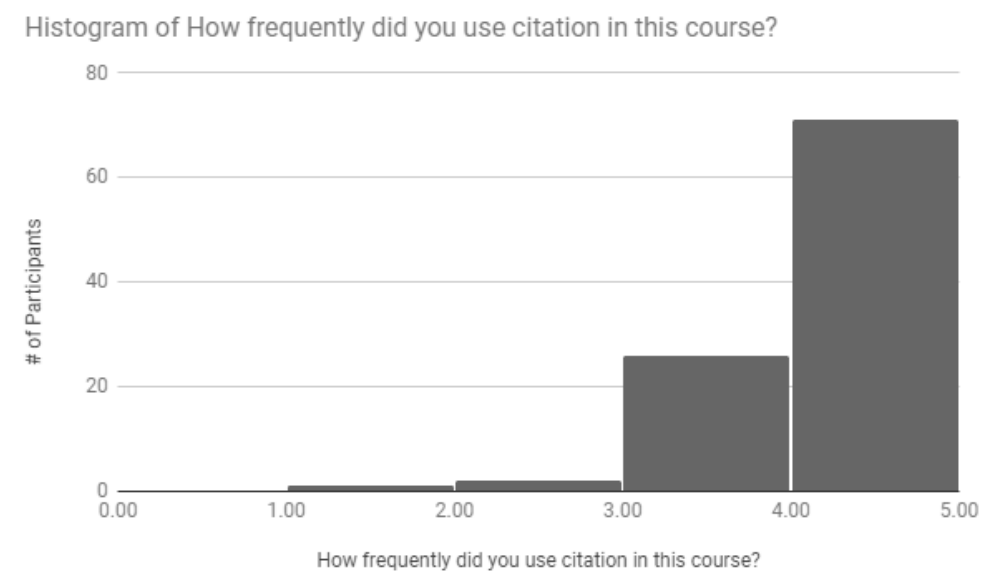

Figure 5. Aggregated (i.e., both DUG and Online programs) survey responses of participant self-reported frequency of citation in writing for the AY 2016-2017 ( $N=124)$.
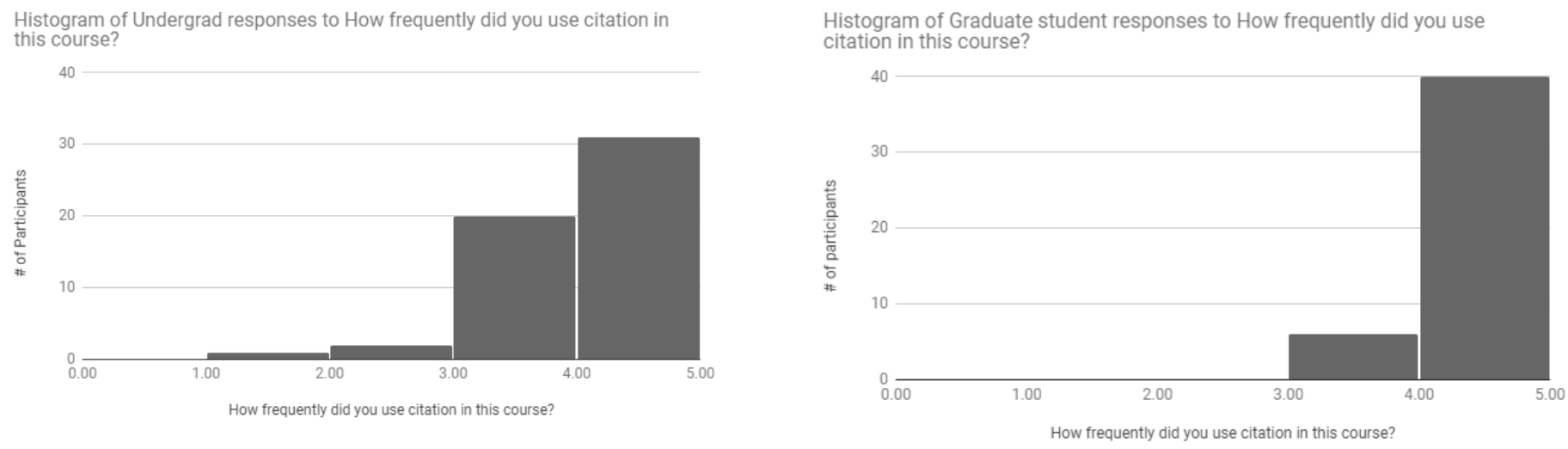

Figures $6 \& 7$. Disaggregated (i.e., Undergraduate and graduate students) survey responses of participant self-reported frequency of citation in writing during a course in AY 2016-17.

ProQuest RefWorks. Figure 8 indicates that the majority of participants in this study use ProQuest RefWorks management software weekly or every day $(M=3.44)$. Figures 9 and 10 show a difference with the frequency of use of ProQuest RefWorks between undergraduate and graduate students. Independent $t$-tests were run to compare the means between the two groups There was a significant difference in the scores for undergraduate students $(\mathrm{M}=3.25, \mathrm{SD}=1.092)$ graduate student responses $(\mathrm{M}=3.65 ; \mathrm{SD}=0.973) ; \mathrm{t}(122)=-2.112, \mathrm{p}=0.037$. Undergraduate students' responses were divided between weekly and daily, while most of the graduate students indicated a daily use of ProQuest RefWorks. 


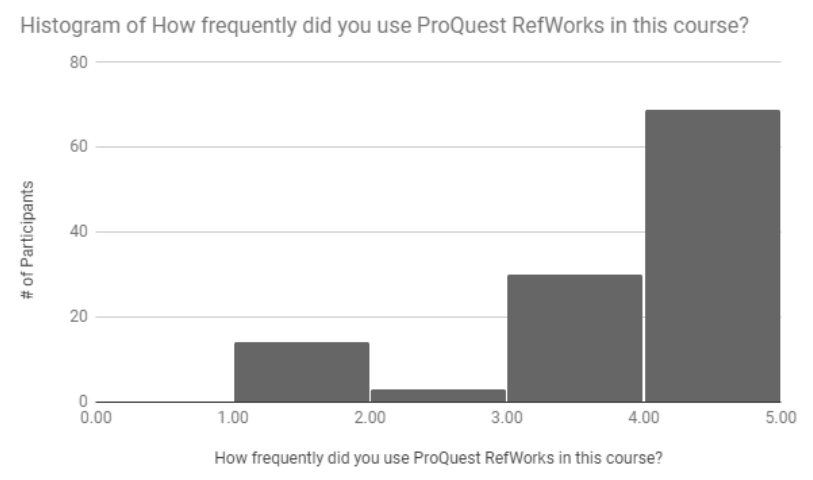

Figure 8. Aggregated (i.e., both DUG and Online programs) survey responses of participant self-reported frequency of ProQuest RefWorks uses for the AY 2016-2017 (N=124).
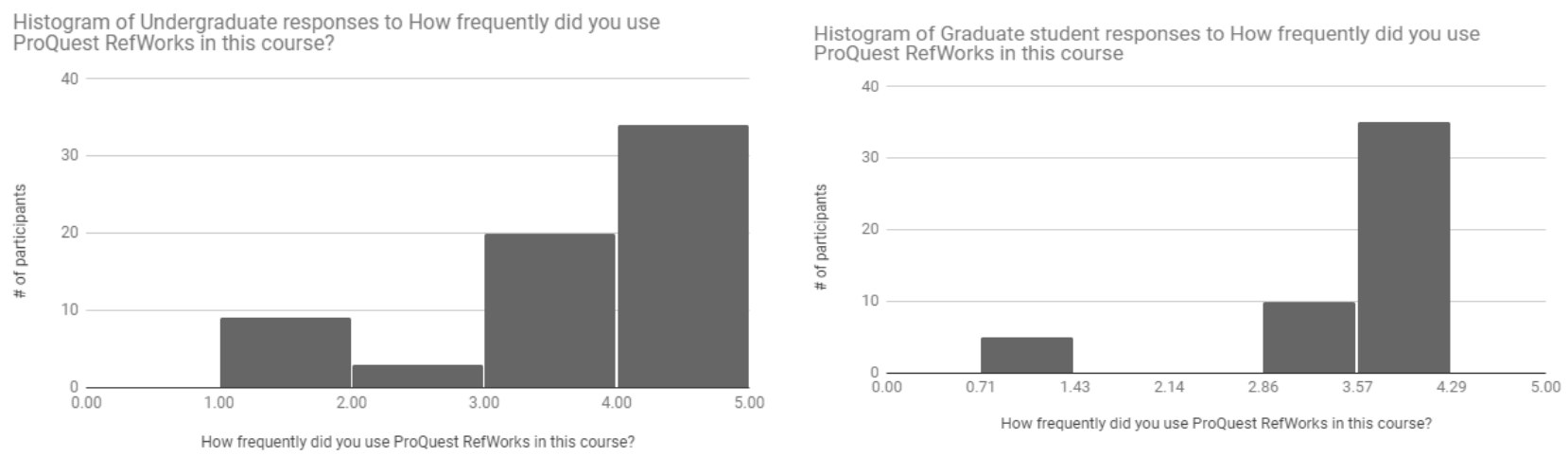

Figures 9 \& 10. Disaggregated (i.e., Undergraduate and graduate students) survey responses of participant self-reported frequency of ProQuest RefWorks use during a course in AY 201617.

\section{Discussion}

This discussion addresses the outcomes we associate with the different data sources including YouTube Module and ProQuest RefWorks analytics as well as the survey results. Further, we discuss the impacts of the ProQuest RefWorks intervention as well as the impact this intervention has had on the IL of the participants in this research. Finally, we describe our next steps for research.

\section{ProQuest RefWorks analytics}

The types of references added to students' RefWorks accounts showed variety from journals and magazines to books, ebooks, and video. Graduate students added six different types of references, while undergraduate students added nine. Dissertations/theses were only added by graduate students. The encyclopedia and Wikipedia references were added by undergraduates who may be unaware that encyclopedia references are not usually used in papers. The high number of journals added may be explained by the class assignments. Most references appear to have been found through the library. This result was reassuring because a video tutorial on database searching using 
the university library resources was part of the video modules which were provided as support resources by participating faculty and not required viewing.

\section{Survey results}

Google Doc proficiency across the sample of participants was expected. Students at the university where the research was conducted are familiar with Google Tools because they are incorporated in many courses. Additionally, the school uses a Google university email service which makes Google Drive applications easily accessible.

Citation in writing findings were surprising. The research team had expected an increase in the citation in writing proficiency of undergraduate students. We assumed that undergraduate students would have had less familiarity with it and that explicit use of citation in writing in the courses in data collection courses would have increased their proficiency. While there was an increase in reported proficiency, it was not significant.

The research team had expected the shift in proficiency with ProQuest RefWorks. The purpose of developing the ProQuest RefWorks YouTube Videos was to address an identified deficiency in students' ability to accurately reference relevant works. Reported frequency of use between the two groups was not surprising given the differentiated level of academic skills expected of undergraduate and graduate students.

The findings from the survey aligned with our expectations but provide a baseline for longitudinal research which we plan to implement. Undergraduate students who use ProQuest RefWorks in multiple courses will hopefully internalize the usefulness of the tool and maintain or increase their proficiency with the tool and increase their frequency of use beyond the "required" course activities.

\section{YouTube video modules and ProQuest RefWorks accounts}

Information literacy incorporates various skills including the use of information to create new knowledge and ethical participation in learning communities (ACRL, 2015). The purpose of this research was to determine whether an intervention had any impact on students' information literacy. The research team developed a series of YouTube videos (i.e., intervention) that were available to support students with creating accounts and using a CMS tool; specifically, ProQuest RefWorks. YouTube analytics indicate that the creating a ProQuest RefWorks account video was viewed 281 times. Analytics from ProQuest RefWorks CMS indicates that 195 student accounts were created and that 582 publications were added to those accounts during the data collection period. This evidence suggests that the intervention did have an impact on students. Students who created accounts and stored reference information in those accounts increased their IL by using tools that support appropriate in-text citation and referencing. In-text citation and referencing are two academic skills that promote ethical participation in learning communities, an essential feature of IL as described by the ACRL (2016).

Graduate students seem to have benefitted from the intervention more than undergraduate students. While the courses selected for this research were from different disciplines, all of the courses had an embedded academic writing component which incorporated the IL skills. Despite the consistency of academic writing across the sample, the undergraduate students reported using in-text citation and the CMS tool less frequently than their graduate student counterparts. As previously suggested, the discrepancy between undergraduate and graduate use of in-text citation and ProQuest RefWorks CMS is likely the result of graduate vs. undergraduate course requirements. Undergraduate courses likely require fewer academic writing assignments than graduate courses. This means that 
undergraduates would use the IL skills of in-text citation and reference less frequently than graduate students.

\section{Next Steps}

The next steps for this research will include: (1) increasing the number of faculty members who use the YouTube Videos introducing students to ProQuest RefWorks and; (2) communicating our findings with our core competency team in order to develop a strategic plan for implementing IL skills across a student's academic career.

Findings from previous research indicate that student's IL is the responsibility of all university faculty, not just the librarians (D'Angelo, Jamieson, Maid, \& Walker, 2017). In order to impact the IL of a greater number of students, the team that conducted this research needs to solicit the support from other faculty members who are willing to embed the video modules into their course activities. We believe that the skills covered within these modules will support the development of student's IL skills through academic activities requiring the use of citation in writing and referencing. The research team would also create a suggested assignment protocol for viewing the video modules and creating student ProQuest RefWorks accounts. Given that IL skills are universal, we are hopeful that our resources will be well received and that other faculty will see the benefit of committing some instructional time to implement these modules. The idea of collaboration across disciplines is suggested by those that developed the Framework (ACRL Appendices, 2015). This interdisciplinary dialogue about IL will hopefully create a pathway for future discussions about other skills, including academic writing.

To further address IL across all students at the university, we will communicate the results with our core competency team. The core competency team is responsible for the review and analysis of data related to IL, therefore our information will hopefully provide them with evidence to support decisions related to strategic planning to support the development of IL for all students across the university. Our evidence indicates that graduate students use ProQuest RefWorks with greater frequency than undergraduate students, therefore further work is needed to support student use of the tool. In addition to our findings, the core competency committee will be informed of prior research suggesting best practices for embedding IL skills throughout all the levels of university coursework.

\section{Acknowledgements}

Research reported in this publication was supported by Center for Teaching and Learning at Chaminade University of Honolulu under Title III grant award number P031W150002. The contents are solely the responsibility of the authors and do not necessarily represent the official views of the institution.

\section{References}

ACRL. (2000). Information literacy competency standards for higher education. Retrieved from http://www.ala.org/ala/mgrps/divs/acrl/standards/informationliteracycompetency.cfm\#st an

ACRL. (2015). Framework for information literacy for higher education. Association of College and Research Libraries. Retrieved from http://www.ala.org/acrl/standards/ilframework

ACRL. (2015). Framework for information literacy for higher education appendices. Association of College and Research Libraries. Retrieved from http://www.ala.org/acrl/standards/ilframeworkapps

American Library Association. (2015). Framework for information literacy appendices. Retrieved from http://www.ala.org/acrl/standards/ilframeworkapps

Journal of the Scholarship of Teaching and Learning, Vol. 19, No. 4, October 2019. 
Benda, C., Limpitlaw, A., \& Estelle-Holmer, S. (2010). Battle of the bibliographic managers: EndNote vs. RefWorks vs. Zotero! American Theological Library Association Summary of Proceedings, 64, 81-87. Retrieved from https://ezproxy.chaminade.edu/login?url=http://search.ebscohost.com/login.aspx?direct=t rue\&db=rfh\&AN=ATLA0001823914\&site=ehost-live

Butros, A., \& Taylor, S. (2010). Managing information: Evaluating and selecting citation management software, A look at EndNote, RefWorks, Mendeley and Zotero. Netting Knowledge: Two Hemispheres/One World: Proceedings of the 36th LAMSLIC Annual Conference, 53-66.

Childress, D. (2011). Citation tools in academic libraries: Best practices for reference and instruction. Reference and User Services Quarterly, 51(2), 143-152.

Duong, K. (2010). Rolling out Zotero across campus as a part of a science librarian s outreach efforts. Science \& Technology Libraries, 29(4), 315-324. Retrieved from http://dx.doi.org/10.1080/0194262X.2010.523309

Emanuel, J. (2013). Users and citation management tools: Use and support. Reference Services Review, 41(4), 639-659. https://www.emeraldinsight.com/doi/abs/10.1108/RSR-02-2013-0007

Fitzgerald, M. A. (2004). Making the leap from high school to college. Knowledge Quest, 32(4), 19-24.

Gilmour, R., \& Cobus-Kuo, L. (2011). Reference management software: A comparative analysis of four products. Issues in Science and Technology Librarianship, (66) DOI: 10.5062/F4Z60KZF Retrieved from http://www.istl.org/11-summer/refereed2.html

Head, A. (2007). Beyond Google: How do students conduct academic research? First Monday, 12(8) doi:10.5210/fm.v12i8.1998

Head, A., Van Hoeck, M., \& Garson, D. (2015). Lifelong learning in the digital age: A content analysis of recent research on participation. First Monday, 20(2) doi:10.5210/fm.v20i2.5857

Hull, D., Pettifer, S. R., \& Kell, D. B. (2008). Defrosting the digital library: Bibliographic tools for the next generation web. PLoS Computational Biology, 4(10), e1000204. doi:10.1371/journal.pcbi.1000204

Jamieson, S. (2017). What the citation project tells us about information literacy in college composition. In B. J. D'Angelo, S. Jamieson, B. M. Maid \& J. R. Walker (Eds.), Information literacy: Research and collaboration across disciplines (pp. 115-138). Fort Collins, CO: The WAC Clearinghouse.

Johnston, B., \& Webber, S. (2003). Information literacy in higher education: A review and case study. Studies in Higher Education, 28(3), 335-352. doi:10.1080/03075070309295

Katz, I. R., \& Elliot, N. (2017). Information literacy in digital environments: Construct mediation, construct modeling and validation processes. In B. J. D'Angelo, S. Jamieson, B. M. Maid \& J. R. Walker (Eds.), Information literacy: Research and collaboration across disciplines (pp. 93-111). Fort Collins, CO: The WAC Clearinghouse.

Kuglitsch, R. Z., \& Burge, P. (2016). Beyond the first year: Supporting sophomores through information literacy outreach. College \& Undergraduate Libraries, 23(1), 79-92. doi:10.1080/10691316.2014.944636

McMinn, H. S. (2011). Library support of bibliographic management tools: A review. Reference Services Review, 39(2), 278-302. doi:10.1108/00907321111135493 ProQuest takes RefWorks to the next level with flow ${ }^{\mathrm{TM}}$. (2013). Retrieved from http:/ /www.proquest.com/about/news/2013/ProQuest-Takes-RefWorks-to-the-NextLevel-with-Flow.html

ProQuest reimagines RefWorks platform to streamline the research and collaboration process. (June 20, 2016). PR Newswire (USA) Retrieved from http://infoweb.newsbank.com/resources/doc/print?p=AWNB

Saunders, L. (2007). Regional accreditation organizations' treatment of information literacy:

Journal of the Scholarship of Teaching and Learning, Vol. 19, No. 4, October 2019. josotl.indiana.edu 
Definitions, collaboration, and assessment. Journal of Academic Librarianship, 33(3), 317-326. Simboli, B., \& Zhang, M. (2002). Citation management and citing-cited data. Issues in Science and Technology Librarianship, 35(2), 1-8.

Tramullas, J., Sánchez-Casabón, A. I., \& Garrido-Picazo, P. (2015). Studies and analysis of reference management software: A literature review. El Profesional De La Información, 24(5), 680-688. doi:10.3145/epi.2015.sep.17

LSU Libraries. (March 13, 2018). Using Citation Management Software. Retrieved from https://guides.lib.lsu.edu/citation management

Weiner, J. (2011). Is there a difference between critical thinking and information literacy? Journal of Information Literacy, 5(2), 81-92.

Wu, Y. D., \& Kendall, S. L. (2006). Teaching faculty's perspectives on business information literacy. Reference Services Review, 34(1), 86-96. doi:10.1108/00907320610648789 